\title{
How to Communicate Nutritional Information to People: the Attitudes of Chile Population Toward Food
}

\author{
Dario Gregori ${ }^{1, *}$, Simonetta Ballali ${ }^{2}$, Maria Gabriella Vecchio ${ }^{2}$, Luis Marcel Valenzuela Contreras ${ }^{3}$, \\ Jorge Baeza Correa ${ }^{3}$, Cecilia Bahamonde Perez ${ }^{4}$, Jorge Barrera Luengo ${ }^{5}$, Edgardo Moyano, \\ Maurizio Arrieta ${ }^{6}$, Angelo Gutierrez ${ }^{6}$, Marco Ghidina ${ }^{7}$, Francesco Giunta $^{8}$ and Marcela Alviña \\ Walker $^{9}$
}

\author{
${ }^{I}$ Unit of Biostatistics, Public Health and Epidemiology, Department of Cardiology, Thoracic and Vascular Sciences, \\ University of Padova,Italy \\ ${ }^{2}$ Prochild ONLUS, Trieste, Italy \\ ${ }^{3}$ Universidad Católica Silva Henríquez, Escuela de Educación Física en Ciencias del Movimiento y Deportes, Santiago \\ de Chile, Chile \\ ${ }^{4}$ Facultad de Ciencias Médicas, Universidad de Santiago de Chile, Chile \\ ${ }^{5}$ Colegio Santo Domingo Savio, Santiago de Chile, Chile \\ ${ }^{6}$ Colegio Camilo Ortuzar Montt, Santiago de Chile, Chile \\ ${ }^{7}$ Zeta Research SrL, Trieste, Italy \\ ${ }^{8}$ Department of IV Anesthesia, University of Pisa, Pisa, Italy \\ ${ }^{9}$ Facultad de Farmacia, Universidad de Valparaiso, Valparaiso, Chile
}

\begin{abstract}
Nutrition labelling on food products represents an important tool for promoting healthy eating in consumers, and to guarantee transparency and clarity on products' characteristics. In an ideal scenario, consumers' better understanding and subsequently better compliance to nutritional facts would result in healthier choices, which could lead to an improved diet and to a reduction in disease-related risk factors. Research is necessary not only in assessing consumers' preferences towards different labels formats, but also to evaluate their ability to process food labels and their disposition towards new regulations concerning labelling. In our study, an ad-hoc survey was conducted to assess general knowledge and use of different labels and nutrition fact information in a Chilean sample ( $\mathrm{n}=1280)$, which was interviewed through a phone survey, performed over a 1-month period, in September 2012. The major part of the interviewees did not habitually read the labels and showed a low interest in paying an additional fee for additional information (89\%). The rest was willing to pay an additional fee of the $5 \%$, in order to get information expressed as Kcal per portion in $68 \%$ of cases compared to per $100 \mathrm{~g}$. Chilean consumers appeared to be interested to nutritional matters and considered nutritional labelling as a proper tool to achieve a healthy lifestyle. Considering the Chilean low knowledge on nutritional labelling, it is necessary to improve nutrition messages and nutrition knowledge among the Chilean population through fast action, especially to help consumers to make health-conscious choices.
\end{abstract}

Keywords: Chilean population, food choices, food label, nutritional information, survey, willingness to pay.

\section{BACKGROUND}

Consumers' attitudes towards food products' purchases and preparation are nowadays at the core of research, given the great effort presently oriented towards reversing overweight and obesity trends, focusing in particular on

*Address correspondence to this author at the Unit of Biostatistics, Public Health and Epidemiology, Department of Cardiology, Thoracic and Vascular Sciences, University of Padova, Via Loredan, 18, 35121 Padova Italy; Tel: +39 049 8275384; Fax: +39 02 700445089;

E-mail:dario.gregori@unipd.it energy intake. Nutrition labelling on food products has emerged as a prominent policy tool to promote healthy eating [1]. Information on the nutritional properties of food is considered as an important mean to reduce what Verbeke calls "information asymmetry" between consumers and food products' suppliers, resulting therefore in informed choices for healthy options and hence for an healthier diet [2]. As considered by Hawley when considering "the science on front-of-package food labels" [3] and more generally the science of labelling, there is a strong need to further investigate consumers' preferences and most of all, use and understanding of food labels, given the growing gap between 
positive attitudes, reported consumption or purchase intentions and real life application of these principles [4]. There is a general agreement on the potential benefits of food labels in helping consumers making informed dietary choices adapted to their individual needs $[4,5]$. Nutritional labelling presents detailed information of food content and its composition, becoming therefore an essential vehicle of communication between food manufacturers and consumers [6]. In an ideal scenario, consumers' better understanding and subsequent better compliance to nutritional facts would result in healthier choices, thus leading to improved diet and a reduction in disease-related risk factors [7]. Different nutrient intake scenarios have been developed in diverse populations, like the Dutch one where, in a recent research conducted by Vyth [8], the potential effects of consuming a diet that complies with the criteria for a front-of-pack on specific outcome were showed, despite their lack in picturing the present situation [8]. Hence, there is no convincing evidence that food labels are an effective means to achieve the desired effect at population level, i.e. a reduction or at least the truncation of current prevalence rates in diet-related disorders. A general overview of scientific peer reviewed literature may show a general agreement on drafting an ideal consumer, which is health conscious [9], reporting a high use of nutritional labels [1] and an even wider understanding of given messages [10]. This scenario however seems to fail in describing the real complexity of the present situation, even initially, when considering comprehension and use outside the Anglo-Saxon's framework, both in terms of population and/or methods. In fact, as well as different populations are considered, as for example in recently published Sharf's study on Hebrew-speaking Israelis [6] or in Gorton's multiethnic New Zealand sample [11], accessibility and proper understanding might vary a lot. In addition, another shift from the ideal model is represented from the real impact of food labelling on nutrition related diseases. As pointed out by Wills, despite 15 years of providing comprehensive nutrition information on food labels in the United States, obesity rates have increased and consumers still appear confused from the tools used to deliver the message [5]. This failure to achieve the desired effects seems particularly marked in those in most urgent need to improve their diet, e.g. children and adolescents [6], as well as overweight and obese individuals [4]. For example, those most concerned with managing their weight, although interested in food labels [12] are also most likely prone to underestimate the caloric content of meals, of both healthy and unhealthy items, resulting in weight gain rather than weight loss [13].

Research needs therefore to be deepened, not only in assessing consumers' preferences towards different labels formats, but also their ability to process food labels and their disposition towards new regulations concerning labelling. Indeed the inclusion of nutritional labels on food items is a resolution that concerns both policy makers and food manufacturers. When considering decision-making process, a resolving matter is the perceived usefulness of the nutritional label, compared to the economic burden implied by the new labelling procedure. Willingness to pay (WTP) is the economic notion used to quantify this usefulness in monetary terms [14], commonly with ad-hoc surveys, where hypothetical conditions or prices are evaluated [15]. Potential price's raises, due to the introduction of new formats, become therefore a crucial step when considering the purchase's decision making process of both repeatedly purchased products and new ones, taking into account that this step takes place in a variety of decisions' contexts [16].

The aim of the current survey was to assess general knowledge and use of different labels and nutrition fact informationin a Chilean sample. To evaluate these parameters, a Computer Assisted Telephone Interview (CATI) was conducted in Santiago del Chile's metropolitan area. Besides, a secondary objective was to estimate the perceived utility that Chilean consumers assign to food labels.

\section{MATERIAL AND METHODS}

\section{Survey Methodology}

A "Computer Assisted Telephone Interview" (CATI) was conducted on a Chilean population-based sample at ZETA Research Ltd'sfacility (www.zetaresearch.eu) from September till October 2012. The interviews were conducted by eighteen experienced CATI operators, Spanish being their mother tongue or graduated in Spanish language. The respondents were verbally informed on the focus of the study and on the following use for scientific purposes and publications. Santiago del Chile's telephone directory was randomly searched to pick participants phone number. Participants were enrolled only if they had previously agreed to the participation and if they completed the full interview.

\section{Survey Domains}

The survey's questionnaire was developed by the authors of the current paper, supported by information obtained from European surveys on food labels and their penetration and impact $[5,17]$ and specific questionnaires assessing choices of reference amounts [18]. Queries have been organized in four main domains, aimed at assessing different aspects of consumers' characteristics. Four main sections have been identified, the first three assessing general data and understanding, and the fourth one precisely considering WTP:

1. The first domain was composed by 12 questions, defining the social background of the interviewees, by gathering basic personal information, including information on the composition of the family, with specific inquiry on the family's size, the presence of children and also details on the highest educational level reached and the yearly income of the family;

2. The second domain (15 questions) was developed around the concept of obesity and nutrition, focusing on interviewees' knowledge of and attitude towards these topics. Perception, awareness, behaviours and remarks on public communications were considered. The interviewees were firstly asked whether they perceived obesity as a societal problem and if their awareness of obesity rooted at a personal level (individual and familiar). Interviewees were asked to rate on 5-point-Likert scales their government's education and information on nutrition and media involvement in sharing nutritional information. In addition, interviewees were asked about their active behaviour towards a healthier life-style; 
Table 1. Socioeconomic Data and Family Composition

\begin{tabular}{|c|c|}
\hline & $\mathbf{N}$ \\
\hline \hline At least one kid in the family & $74 \%(943)$ \\
\hline Low-Medium SES & $52 \%(660)$ \\
\hline Middle school education & $38 \%(479)$ \\
\hline University education & $37 \%(466)$ \\
\hline
\end{tabular}

3. The third domain (30 questions) focused on nutritional information, assessing interviewees' habits to use information provided on the packages and on their actual understanding. The specific nutritional tools investigated were the Guidelines Daily Amounts (GDA) and the Nutritional Facts on the back-of-pack (BOP). Participants were asked to define the meaning of each expressions used in the labels (from "per $100 \mathrm{~g}$ " up to "per portion"); answers' correctness was afterwards evaluated from the interviewers, that assigned a judgment going from "completely correct" to "totally wrong", without informing the interviewees. Scientific definitions were previously given to the interviewees in order to uniform the evaluation method. After assessing the knowledge on the contents of nutritional labels, interviewees were asked to give an evaluation on the usefulness, completeness and pertinence of the labelling tools, not only from an external perspective, but also referring to their decision-making process when purchasing such products. A specific question on the usefulness of the front-of-pack (FOP) labels was inserted at this stage, in order to match the choosing behaviour to the knowledge and perceptions previously indicated by interviewees;

4. The fourth domain outlined in 4 questions was a hypothetical scenario, describing the possibility of a new FOP labelling and the potential general rise of food products' prices due to packaging's re-design. Participants were presented with the possibility of a mandatory requirement for nutritional labels in food products. The interviewer explained that these policies might result in an increase of food prices, due to the necessity of having to re-design the packaging. To assess interviewees' willingness to pay, questions on the maximum accepted increase were made, asking to indicate their preference on the FOP nutritional tool that they considered to be the most useful. The last section was devoted to the estimation of the WTP for a new FOP label.

\section{Sampling Plan}

A stratified sampling plan was adopted. The planned sample sizes were computed to ensure precision of the estimates at the European global level. Population size adopted in the sampling plan was from United Nations Databank (www.un.org/esa/population).

The survey required a total of 1280 interviews, performed from September to October 2012. Participants were selected using random digital dialling.

\section{Statistical Analysis}

Survey responses were estimated along with their confidence intervals using the Survey library of R [19]. The double-bounded WTP model was estimated using the R system [20]. Model selection was done using AIC (Akaike Information Criterion) as criterion [21].

\section{RESULTS}

\section{First Domain}

A total of 1282 closed interviews were analysed. The majority of respondents were Chilean $(95 \%)$ women $(63 \%)$, older than 45 years old $(58 \%)$. The $73 \%$ of the interviewed stated to have at least one child. Socio-economic aspects and family composition are presented in Table $\mathbf{1}$.

\section{Second Domain}

When interviewed on obesity and overweight issues, the $39 \%$ declared to have a weight problem, while the $34 \%$ stated that at least one member of his/her family was obese or overweight. Among the interviewees, $46 \%$ answered to eat just in case of hunger, while they declared to do more physical activity after a heavy meal in $6 \%$ of cases. Personal experience and referral to the medical doctor were defined in the $32 \%$ and $37 \%$ of cases as the main tool to build a nutritional knowledge. In $56 \%$ of cases, respondent stated that the government had not sufficiently invested in public education on nutrition subjects and specifically on overweight and obesity. Chilean consumers were asked to express an opinion on currently developed communication strategies, stating in the $37 \%$ of cases that the service given was insufficient. Advertising was accounted as the most efficient strategy in $33 \%$ of cases. Physical activity was considered as a preventive strategy for weight related issues by $97 \%$ of respondents and the $66 \%$ of cases declared to do exercise regularly.

\section{Third Domain}

When asked which were the first three words that the participants would associate to a label, the major part of them paid attention to the total fats, calories and total sugars. Consumers were stratified by the habit of reading or not nutritional labels, and overall results were considered as well. The $35 \%$ of the interviewed habitually didn't read nutritional label while the $55 \%$ of the respondents declared to habitually read. Significant differences were found when comparing the two groups, with consumers who habitually read labels more interested on the specific composition of the products. Data were stratified by the habit to read nutritional facts on food packages. Consumers appeared to be mostly interested in enquiring the total fat content $(46 \%)$ and the calories $(35 \%)$ of a product when considering nutritional labels. All data are presented in Table 2. When investigated the recommended daily intake for a balance diet, $43 \%$ was not able to answer. Consumers who declared to have a sufficient nutritional knowledge, said in the $63 \%$ of cases that it was because they had experience, both personally and within their family, on health problem related to weight. The $59 \%$ of the interviewees declared to read labels in order to understand the composition of the product. 
Table 2. First item Recalled from Interviewees when Questioned on Nutritional Label. Answers are Stratified by the Habit to read Nutritional Facts of Food Products. All Results are given as Relative Frequencies (\%) with the Absolute Value in Brackets

\begin{tabular}{|c|c|c|c|c|}
\hline & Not Reading the Label & Reading the Label & Combined & Test Combined \\
\hline \hline Total Fat & $36(161)$ & $52(434)$ & $46(596)$ & $\mathrm{p}<0.001^{*}$ \\
\hline Calories & $27(120)$ & $40(335)$ & $35(455)$ & $\mathrm{p}<0.001^{*}$ \\
\hline Total Sugar & $28(126)$ & $37(304)$ & $33(427)$ & $\mathrm{p}=0.009 *$ \\
\hline Salt & $21(95)$ & $40(331)$ & $18(231)$ & $\mathrm{p}<0.001^{*}$ \\
\hline Cholesterol & $13(60)$ & $21(171)$ & $15(197)$ & $\mathrm{p}=0.005^{*}$ \\
\hline Carbohydrates & $9(41)$ & $19(156)$ & $22(70)$ & $\mathrm{p}<0.001 *$ \\
\hline No answer & $15(69)$ & $3(28)$ & $5(69)$ & $\mathrm{p}<0.001^{*}$ \\
\hline Other & $11(12)$ & $28(58)$ & $6(49)$ & $\mathrm{p}=0.529$ \\
\hline Calcium & $4(20)$ & $4(30)$ & $3(34)$ & $\mathrm{p}=0.937$ \\
\hline Iron & $3(15)$ & $3(21)$ & $2(22)$ & $\mathrm{p}=0.898$ \\
\hline Portion size & $3(13)$ & $1(3)$ & & $\mathrm{p}=0.104$ \\
\hline Grams of product & & $2(19)$ & \\
\hline
\end{tabular}

*Indicates a Significant p-value at 0.05 Level

Preferences on labels and appropriateness of serving definitions are presented in Table 3. Respondents were asked to indicated the most caloric items following two different ways of defining products' calories (per 100 gr and per portion), and in both cases they showed to select the wrong caloric item of the mealin most of cases $(76 \%$ and $60 \%$ of cases respectively). Generally the respondents declared to define the necessary energy intake for each meal based on the caloric values of food in $39 \%$ of cases, while $29 \%$ were driven by experience. A significant difference was found between those belonging to the group habitually reading labels and those who were not $(\mathrm{p}<0.05)$. When asked for preference on label, 52\% defined per portion method as the favourite one. Participants agreed on personal responsibility as the main driver of meal intake decisions in $57 \%$ of cases.

Table 3. Preference and Knowledge on Sizing Method on Nutritional Labels. All Data are Percentage

\begin{tabular}{|c|c|}
\hline & Frequency \\
\hline \multicolumn{2}{|c|}{ Correctness of Serving Definition } \\
\hline \hline \multicolumn{2}{|c|}{ peogr } \\
\hline No answer/Does not know & $44(40-48)$ \\
\hline Wrong & $22(17-27)$ \\
\hline Partially correct & $14(9-19)$ \\
\hline Totally correct & $17(12-22)$ \\
\hline per 100 Kcal \\
\hline No answer/Does not know & $70(67-73)$ \\
\hline Wrong & $12(7-17)$ \\
\hline Partially correct & $6(0-12)$ \\
\hline
\end{tabular}

\begin{tabular}{|c|c|}
\hline Totally correct & $9(4-14)$ \\
\hline \multicolumn{2}{|c|}{ per Portion } \\
\hline No answer/Does not know & $47(43-51)$ \\
\hline Wrong & $15(10-20)$ \\
\hline Partially correct & $8(3-13)$ \\
\hline Totally correct & $26(21-31)$ \\
\hline \multicolumn{2}{|c|}{ Preference of Serving Definition } \\
\hline per 100gr & $5(0-11)$ \\
\hline per 100kcal & $22(16-18)$ \\
\hline per portion & $62(58-66)$ \\
\hline
\end{tabular}

\section{Fourth Domain}

In general, the interviewees showed a low interested in paying an additional fee for additional information, the $89 \%$ declared they would not pay more, while the rest were ready to pay an additional fee of the 5\% in (see Fig. 1). The added price would most likely be paid in order to get information expressed as Kcal per portion in $68 \%$ of cases.

\section{DISCUSSION}

The continuous rise of obesity and diet-related chronic diseases have set the urgency to retrieve, at a public health level, new approaches, aimed at tackling worldwide epidemic [22]. Daily food consumption has systematically changed within both developed and more recently, developing countries, with an increased consumption of processed foods [6]. Food labelling is therefore considered as an essential tool for the promotion of healthy nutritional practice [23], and as an information source which enablesconsumers to make informed decisions regarding 


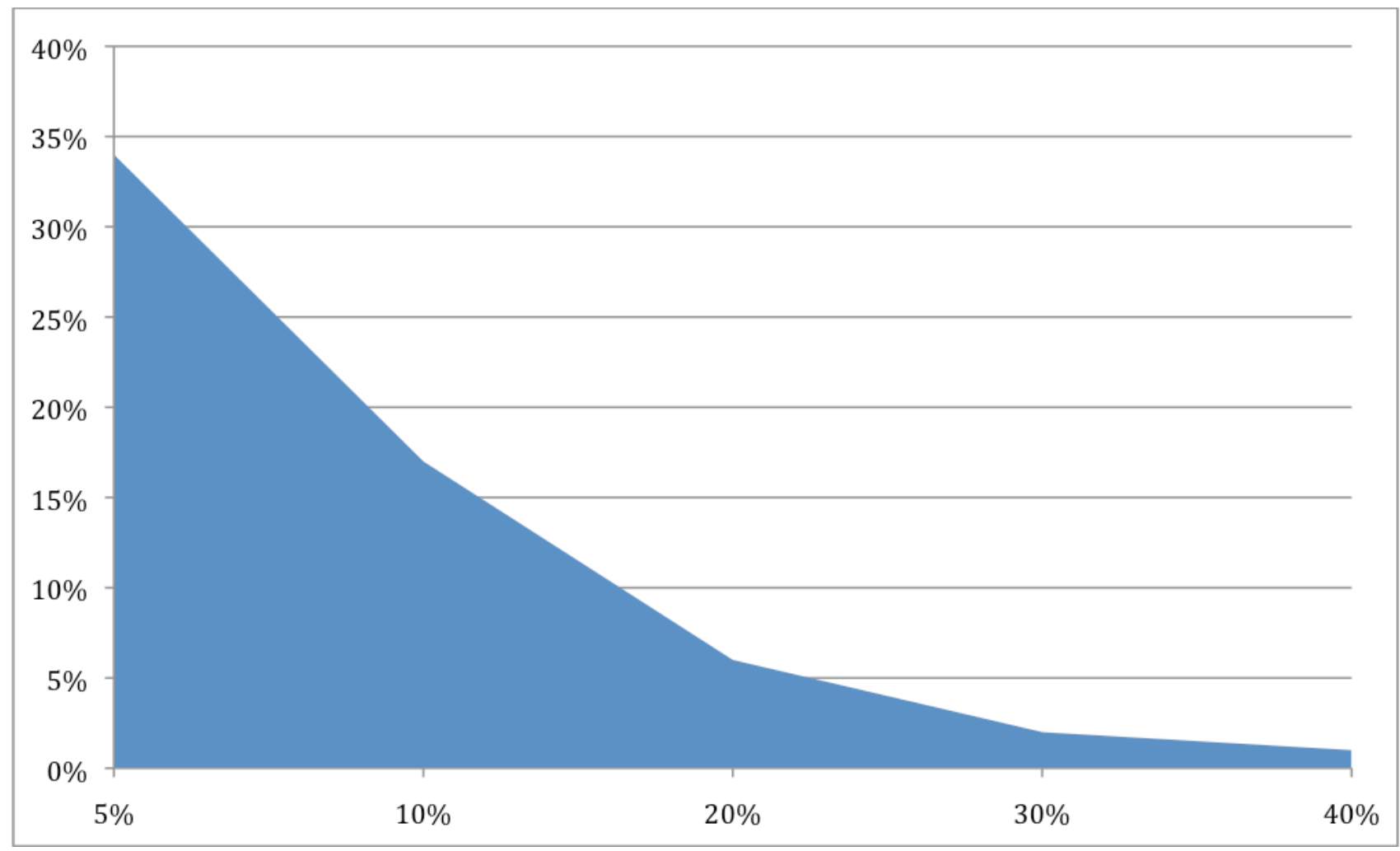

Fig. (1), Willingness to pay in Chilean consumers. On the abscissa, the WTP is expressed as additional fee to be added to the original price; while on the ordinate relative frequencies are expressed.

their dietary habits. Food labels are different from food to food, and the major part of variables include the type and number of nutrients labelled, the reference values used, whether the information appears on front-of-pack (FOP) or back-of-pack (BOP) and whether the label gives any interpretative guidance to the consumer. In a hypothetical scenario, which is still far from being reached, informed consumers would make healthier choices, leading to a control of obesity spread [24]. Even leaving aside the debate on healthy definition and which categorization method should be preferably used [25], the hypothetical scenario seem to be undermined at its earliest point, with studies showing that there is a lack in consumers' knowledge when questioned, consumers would usually claim to understand what is or is not healthy, but that they acknowledged confusion about how to put generalised dietary advice into practice [25]. Consumers knowledge, understanding and use of labels is in the latter instance the concluding argument in labelling development and eventually in public health programmes efficacy.

Research on the European ground has investigated on consumers understanding of nutritional labels, raising yet another issue on the potential factors affecting the gap between labelling implementation and its real efficacy. Grunert and colleagues underlined that even when understanding appeared to be widespread, use seemed to be way lower, suggesting lack of motivation as detrimental factor [10]. Looking closer, understanding was not found as homogeneously distributed in the European population, nor when considering country peculiarities [26], neither when evaluating different socio-economic or demographic backgrounds [27].
The aim of the present research was to assess general knowledge and use of different labels and nutrition fact information on a different ground, where for instance, nutrition labelling is mandatory on some or all pre-packaged food, differently from what happens in Europe where nutrition labelling voluntarily follows state-sponsored guidelines. The prevailing view in countries with mandatory and voluntary labelling alike is that standard methods and expression tools are preferable to a multitude of different nutrition labels [28]. As considered in a previous research on European consumers held from the same authors, at regulatory level it still remains broad disagreement on what format is most effective at influencing consumer behaviour. The present research aimed at reflecting on consumer perspective and their format preferences, assessing through practical examples their actual understanding when presented with different formats. As considered in Campos review [4] the use of nutrition labels varied considerably across population subgroups, being particularly high among individuals with health conditions and special dietary requirements, while notably lower among children, adolescents and older adults, where obesity is rapidly spreading nowadays. Chilean consumers appeared to have an overall low knowledge on nutrition and nutritional issues that they addressed mostly as a lack of proper education from governments and politicians.

When interviewees were asked on specific preferences on label format, the majority the sample stated to prefer when nutrition facts were given as $\mathrm{k}$ calories per portion. This consideration is in line with previous researches. In 2008 Van Kleef investigated consumers' preference on serving information by interviewing an UK sample on newly 
designed labels [29]. He concluded that calories per portion were clearly seen as an instrument to assess the nutritional content of what one was actually buying or consuming, while calories per $100 \mathrm{~g}$ were mostly cited as an instrument for comparison between different choices. Drewnowski and colleagues analysed in 2009 the effect of using different methods of sizing in nutritional profiles, showing that models based on serving sizes were preferable for positive subscores [18]. There is significant on-going debate amongst stakeholders as to the best FOP labelling approach and alongside this, emerging evidence suggested that the plethora of schemes and their differing presentation on package may cause confusion for the consumer [30]. When specifically asked for definition of different methods to describe nutrient calories, Chilean respondents appeared not to have clear ideas. Similar was found in Cowburn's review [1], where the studies retrieved that although some consumers could understand some of the information on nutrition labelling, in general they reported finding nutrition labelling confusing. In our study, the considered sample presented very low prevalence of correct answers, showing a better performance when asked to define per portion label presentation. When the participants were questioned on fast and quick calories counts within meals, the results showed a low percentage of correct answers, with a positive peak only when questions were involving per portion definition. This links with Hodgkins' study [31], that suggested that heuristic processing is more likely to be employed by individuals with a low level of knowledge about a subject and/or lack of background or detailed information, while systematic processing tends to be employed when people have both the ability and willingness to process more information. Taken the peculiarity of the interview, with interviewers instructed to keep the answer fast in order to imitate supermarket decision making process [32], respondents appeared to have unclear ideas on how to correctly figure their energy intake. As considered from Campos [4], research to date has highlighted the need to balance the complexity of information presented on labels with consumers' ability to process this information in a quick and meaningful manner. As proven from Chilean research, nutrition labels requiring calculations with respect to nutrient amounts and serving sizes are confusing to many consumers, particularly those with lower education and literacy skills [33].

The present survey enquired also on Chilean consumers' willingness to pay (WTP) a higher fee in order to get additional information on commonly consumed food products. WTP is a well-accepted parameter used to measure the evaluation of health benefits, consistent with the principles of welfare economies and cost-benefit analysis [34], representing a reliable way to understand the perceived utility of nutritional label for consumers [35].

The WTP assessment followed the general survey on consumers' perception of their nutritional status, in order to set the question into a wider nutritional framework. As seen in a 2009 experimental study [36], the immediacy of understanding plays an important role. Results generally showed that consumers' WTP was higher for the products with nutritional information than the products without nutritional information, suggesting that consumers' evaluation of products with nutritional information could vary depending on the type or amount of information on the label. The present research showed a remarkably low WTP in the whole sample, with a higher accordance towards an increase in product fee only if nutrition facts would be expressed with the "per portion" method. Also Drichoutis in his study demonstrated that the tested sample unanimously preferred the reduced cognitive effort associated with the "per portion" sizing method, when compared to the other two choices. According to Loureiro et al. [37] who studied WTP for a specific product, factors affecting consumer preferences for nutritional labelling appear to be strictly linked to the health status of the respondents: particularly in the present study, those who perceive themselves as obese seem to be more willing to pay for nutritional information.

In conclusion, Chilean consumers appeared to be interested to nutritional matters and consider nutritional labelling as a proper tool to achieve a healthy lifestyle, but presented a low knowledge on nutritional labelling, preferring a more direct way of calories expression, as the «per portion» one, instead of $100 \mathrm{gr}$. The perceived value of additional information on the package appears in any case very low, adding that they would pay a higher fee for information when expressed per portion. In summary, our study highlights the need for fast action to improve nutrition messages and nutrition knowledge among the Chilean population, to help consumers to make health-conscious choices of products that fit their preferred dietary patterns. Hence communication should be using simple formats; this should help educated and less educated consumers alike to make better decisions.

\section{CONFLICT OF INTEREST}

The authors confirm that this article content has no conflicts of interest.

\section{ACKNOWLEDGEMENTS}

This research was partially funded by an unrestricted grant of the University of Padova and of Prochild ONLUS. The research did benefit also from a technical grant of ZETA Research Ltd for conducting the Survey. The work has been partially supported by an unrestricted grant of the Italian Ministry of Foreign Affairs under the program "Programmi di alta rilevanza scientifica e tecnologica Italia-Messico".

\section{REFERENCES}

[1] Cowburn G, Stockley L. Consumer understanding and use of nutrition labelling: a systematic review. Public Health Nutr 2005; 8(1): 21-8.

[2] Verbeke W. Agriculture and the food industry in the information age. Eur Rev Agric Econ 2005 2005; 32(3): 347-68.

[3] Hawley KL, Roberto CA, Bragg MA, et al. The science on frontof-package food labels. Public Health Nutr 2012; 22: 1-10.

[4] Campos S, Doxey J, Hammond D. Nutrition labels on prepackaged foods: a systematic review. Public Health Nutr 2011; 14(8):1496-506.

[5] Wills JM, Schmidt DB, Pillo-Blocka F, et al. Exploring global consumer attitudes toward nutrition information on food labels. Nutr Rev 2009; 67 (Suppl 1): S102-6.

[6] Sharf M, Sela R, Zentner G, et al. Figuring out food labels. Young adults' understanding of nutritional information presented on food labels is inadequate. Appetite 2012; 58(2): 531-4.

[7] Borgmeier I, Westenhoefer J. Impact of different food label formats on healthiness evaluation and food choice of consumers: a randomized-controlled study. BMC Public Health 2009; 9: 184. 
[8] Vyth EL, Hendriksen MA, Roodenburg AJ, et al. Consuming a diet complying with front-of-pack label criteria may reduce cholesterol levels: a modeling study. Eur J Clin Nutr 2012; 66(4): 510-6.

[9] Kaskutas LA, Greenfield TK. The role of health consciousness in predicting attention to health warning messages. American journal of health promotion: Am J Health Promot 1997 ; 11(3): 186-93.

[10] Grunert KG, Fernandez-Celemin L, Wills JM, et al. Use and understanding of nutrition information on food labels in six European countries. Zeitschrift fur Gesundheitswissenschaften. J Public Health 2010; 18(3): 261-77.

[11] Gorton D, Ni Mhurchu C, Chen MH, et al. Nutrition labels: a survey of use, understanding and preferences among ethnically diverse shoppers in New Zealand. Public Health Nutr 2009; 12(9): 1359-65.

[12] Vyth EL, Steenhuis IH, Vlot JA, et al. Actual use of a front-of-pack nutrition $\log$ o in the supermarket: consumers' motives in food choice. Public Health Nutr 2010; 13(11): 1882-9.

[13] Chernev A. The Dieter's Paradox. J Consum Psychol 2011; 2(2): 178-83.

[14] Klose T. A utility-theoretic model for QALYs and willingness to pay. Health Econ 2003; 12(1): 17-31.

[15] Marjon van der P, Shiell A, Au F, et al. Convergent validity between a discrete choice experiment and a direct, open-ended method: comparison of preferred attribute levels and willingness to pay estimates. Soc Sci Med 2008; 67(12): 2043-50.

[16] Hoyer WD. An Examination of Consumer Decision Making for a Common Repeat Purchase Product. J Consum Res 1984;11(3): 822-9.

[17] Storcksdieck GBS, Celemin LF, Larranaga A, et al. Penetration of nutrition information on food labels across the EU-27 plus Turkey. Eur J Clin Nutr 2010; 64(12): 1379-85.

[18] Drewnowski A, Maillot M, Darmon N. Should nutrient profiles be based on $100 \mathrm{~g}, 100 \mathrm{kcal}$ or serving size? Eur J Clin Nutr 2009; 63(7): 898-904.

[19] Lumley T. Analysis of complex survey samples. J Stat Softw 2004; 9(1):1-19.

[20] R Development Core Team. R: A language and environment for statistical computing. Vienna (Austria): R Foundation for Statistical Computing 2011.

[21] Bozdogan H. Model selection and Akaike's information criterion (AIC): the general theory and its analytical extensions. Psychometrika 1987; 52: 345-70.

[22] Ollberding NJ, Wolf RL, Contento I. Food label use and its relation to dietary intake among US adults. J Am Diet Assoc 2010; 110(8): 1233-7.
[23] Amital H, Gilburd B, Shoenfeld Y. Intelligent nutrition: healthpromoting mechanisms of probiotics. Isr Med Assoc J 2003; 5(11): 812-3.

[24] Gallos LK, Barttfeld P, Havlin S, et al. Collective behavior in the spatial spreading of obesity. Sci Rep 2012; 2: 454.

[25] Lobstein T, Davies S. Defining and labelling 'healthy' and 'unhealthy' food. Public Health Nutr 2009; 12(3): 331-40.

[26] Grunert KG, Wills JM, Fernández-Celemín L. Nutrition knowledge, and use and understanding of nutrition information on food labels among consumers in the UK. Appetite 2010; 55(2): 177-89.

[27] Carrillo E, Varela P, Fiszman S. Influence of Nutritional Knowledge on the Use and Interpretation of Spanish Nutritional Food Labels. J Food Sci 2012; 77(1): H1-H8.

[28] Nestle M, Ludwig DS. Front-of-package food labels: public health or propaganda? J Am Med Assoc 2010; 303(8): 771-2.

[29] van Kleef E, van Trijp H, Paeps F, et al. Consumer preferences for front-of-pack calories labelling. Public Health Nutr 2008; 11(2): 203-13.

[30] FSA. Comprehension and use of UK nutrition signpost labelling schemes Congritive Testing Report. London: Food Standards Agency 2009.

[31] Hodgkins C, Barnett J, Wasowicz-Kirylo G, et al. Understanding how consumers categorise nutritional labels: a consumer derived typology for front-of-pack nutrition labelling. Appetite 2012; 59(3): 806-17.

[32] Waterlander WE, Scarpa M, Lentz D, et al. The virtual supermarket: an innovative research tool to study consumer food purchasing behaviour. BMC Public Health 2011; 11: 589.

[33] Nayga RM, Lipinski D, Savur N. Consumers' Use of Nutritional Labels While Food Shopping and At Home. J Consum Aff 1998; 32(1): 106-20.

[34] Gafni A. Willingness-to-pay as a measure of benefits. Relevant questions in the context of public decisionmaking about health care programs. Med Care 1991; 29(12): 1246-52.

[35] Prathiraja PHK, Ariyawardana A. Impact of Nutritional Labeling on Consumer Buying Behavior 2003. Sri Lankan J Agric Econ 2003; 5 (1): 35-46

[36] Drichoutis AC, Lazaridis P , Nayga RM. Would Consumers Value Food-Away-From-Home Products With Nutritional Labels? Agribusiness 2009; 25(4): 550-75.

[37] Loureiro MLGA, Nayga RMJ. Do consumers value nutritional labels? Eur RevAgric Econ 2006; 33(2): 249-68.

Received: January 23, 2013

Revised: January 30, 2013

Accepted: March 04, 2013

(C) Gregori et al.; Licensee Bentham Open.

This is an open access article licensed under the terms of the Creative Commons Attribution Non-Commercial License (http://creativecommons.org/licenses/by-nc/3.0/) which permits unrestricted, non-commercial use, distribution and reproduction in any medium, provided the work is properly cited. 